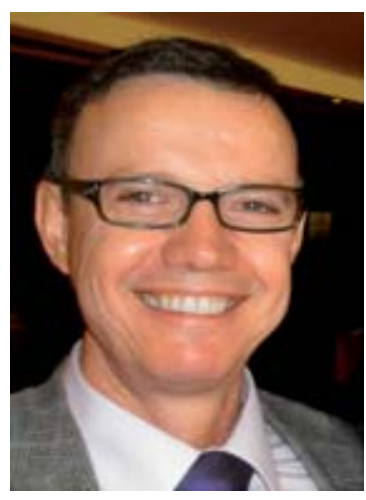

Vicente Hernández Franco Director

\title{
el orientador es un profesional no-prescindible para la equidad educativa
}

\begin{abstract}
«La mejora de los niveles educativos del alumnado radica principalmente en la eficacia de los sistemas de apoyo a la educación, tanto si se ubican en la escuela, como si se ofrecen desde servicios especializados que proporcionan orientación y asistencia a los profesores y a la dirección del centro».
\end{abstract}

ANDREAS SCHLEICHER'.

icen que se acercó una profesora a una de sus alumnas de cuarto de ESO al ver que estaba escribiendo algo con su móvil,y como para pillarla le preguntó: "Dime, ¿cuántas patas tiene un artrópodo?" Ante lo interesante de la pregunta, la chica abrió mucho sus ojos y, levantando las cejas, respondió con total tranquilidad: "¡Ay, señorita, cómo me gustaría tener yo los mismos problemas que usted tiene!".

La incorporación efectiva de los profesionales de la psicología,la pedagogía y el trabajo social;su integración en los organigramas de los centros a través de los departamentos de orientación; el reconocimiento de su estatus docente $y$, por tanto, de miembros del claustro de centro, es uno de los principales legados positivos que permanecen después de más de veinte años desde la implantación de la LOGSE. En un principio, a partir de 1996 sólo se recogieron en los conciertos educativos las horas de dedicación para el orientador educativo en la etapa de Secundaria Obligatoria. La demanda social y el prestigio ganado por estos profesionales desde entonces han supuesto que algunas comunidades autónomas hayan incorporado en los últimos años en el concierto educativo horas para el orientador educativo también en las etapas de Infantil y Primaria. Incluso en algunas, como Castilla y León y recientemente en La Rioja, al profesional que desempeña la función de orientador educativo en los centros concertados de Educación Infantil y Educación Primaria se le reconocen plenas competencias para asumir las funciones generales de los Equipos de Orientación Educativa y Psicopedagógica, lo que supone el pleno reconocimiento por la administración educativa de su responsabilidad y competencia profesional.

Ante los problemas que presenta nuestro sistema educativo, existe un fuerte consenso en señalar que las horas por unidad concertada establecidas para los profesionales de la Orientación Educativa en las distintas etapas son claramente insuficientes para atender a todas las necesidades que les llegan a estos profesionales desde los diferentes miembros de la comunidad educativa. Los recortes en educación están también llegando a estos servicios esenciales en la atención a los distintos tipos de alumnos con barreras de acceso al currículo. Así, en la Comunidad de Madrid en este curso se han eliminado de los conciertos de Bachillerato y Ciclos Formativos de Grado Superior las horas que se concedían para el orientador, lo que puede provocar un importante retroceso en la atención orientadora a los alumnos de estas etapas, consideradas como momentos evolutivos críticos en la toma de decisiones vocacionales de nuestros jóvenes.

Ofrecemos en este número de Padres y Maestros un conjunto de artículos en torno a una de las principales funciones específicas y propias del orientador educativo: la evaluación psicopedagógica. El buen orientador, parafraseando a Neruda, es para sus estudiantes lo que la primavera es para los cerezos: su misión es hacer posible que florezcan y lleguen a ofrecer a nuestra sociedad sus mejores frutos.

"Quiero hacer contigo lo que la primavera hace con los cerezos». Pablo NerudA. «Poema XIV». Veinte poemas de amor y una canción desesperada.

\footnotetext{
I Coordinador del Informe PISA de la OCDE. 2006. La mejora de la calidad y de la equidad en la educación: retos y respuestas políticas. Fundación Santillana.

http://www.fundacionsantillana.com/upload/ficheros/paginas/200906/xx_semana_monografica.pdf
} 